Sule Arican*, Gulcin Hacibeyoglu, Sinan Oguzhan Ulukaya, Gamze Avcioglu, Ruhiye Reisli, Sema Tuncer Uzun and Ozcan Erel

\title{
Ischemia-modified albumin (IMA) and dynamic thiol-disulfide homeostasis in patients with postherpetic neuralgia
}

https://doi.org/10.1515/labmed-2018-0211

Received December 27, 2018; accepted August 27, 2019; previously published online September 17, 2019

\section{Abstract}

Background: Ischemia-modified albumin (IMA) is an isotype of albumin that increases under oxidative stress, and plasma thiols are main defense mechanisms against oxidative stress. The objective of this study was to investigate thiol-disulfide homeostasis and serum IMA levels in postherpetic neuralgia (PHN) patients.

Methods: A total of 29 PHN patients and 30 healthy controls were included in the study. Serum total and native thiol concentrations and serum disulfide concentration were measured using the method described by Erel and Neselioglu. The albumin cobalt binding test was used to measure serum IMA levels.

Results: Serum IMA levels were $1.21 \pm 0.58 \mathrm{AU}$ and $0.75 \pm 0.09 \mathrm{AU}$ in the PHN and control groups, respectively $(\mathrm{p}<0.001)$. Serum total thiol concentrations were found to be $421.62 \pm 90.28 \mu \mathrm{mol} / \mathrm{L}$ and $598.36 \pm 73.63 \mu \mathrm{mol} / \mathrm{L}$ in the PHN and control groups, respectively $(\mathrm{p}<0.001)$. Serum native thiol concentrations were found to be $365.75 \pm 92.07 \mu \mathrm{mol} / \mathrm{L}$ and $531.90 \pm 72.9 \mu \mathrm{mol} / \mathrm{L}$ in the PHN and controlgroups, respectively $(\mathrm{p}<0.001)$. Serum disulfide concentrations were found to be $33.23 \pm 5.33 \mu \mathrm{mol} / \mathrm{L}$ and $27.93 \pm 7.81 \mu \mathrm{mol} / \mathrm{L}$ in the PHN and control groups, respectively $(p=0.003)$. The native thiol/total thiol ratio was significantly lower, and the disulfide/total thiol and

\footnotetext{
*Correspondence: Sule Arican, MD, Department of Anaesthesiology, University of Necmettin Erbakan, Medical Faculty, Yunus Emre Mah. Bağlarbaşı Sok., No: 281, 42080 Meram-Konya, Turkey, Phone: +00903322236600, E-Mail: drsulearican@hotmail.com Gulcin Hacibeyoglu, Sinan Oguzhan Ulukaya, Ruhiye Reisli and Sema Tuncer Uzun: Department of Anaesthesiology, University of Necmettin Erbakan, Medical Faculty, Konya, Turkey Gamze Avcioglu and Ozcan Erel: Department of Medical Biochemistry, Faculty of Medicine, Yildirim Beyazit University, Ankara, Turkey
}

disulfide/native thiol ratios were significantly higher in the PHN group compared to the controls.

Conclusions: IMA levels are high and dynamic thiol/ disulfide homeostasis is disrupted in PHN patients.

Keywords: ischemia-modified albumin; oxidative stress; postherpetic neuralgia; thiol/disulfide.

\section{Introduction}

Herpes zoster (HZ) results from reactivation of the varicella zoster virus (VZV) which remains latent in the dorsal root ganglion following the initial infection. Reactivation of VZV is associated with decreased cell-mediated immunity [1]. Several factors including diabetes, cancer, surgery, organ transplantation, stress and negative life events have been stated as risk factors for HZ [2-6]. Psychological stress is a widely recognized risk factor and is thought to be a trigger for HZ [6].

Neuralgia along a dermatome and unilateral rash are typical clinical symptoms of HZ. Although rash usually improves within 2-4 weeks, HZ complications may develop. The most common complication of $\mathrm{HZ}$ is postherpetic neuralgia (PHN), which is generally defined as pain lasting longer than 90 days after improvement of rash [7, 8]. Several risk factors for the development of PHN in $\mathrm{HZ}$ patients have been reported including age, gender, clinical features of HZ episode, chronic morbidity, immunosuppression and cancer [9].

Thiols are organic sulfur derivatives containing sulfhydryl residues $(-\mathrm{SH})$ in their active regions. Thiols easily react with oxygen-containing free radicals to form disulfides. This is a defense mechanism against oxidative stress. Disulfide bonds can be reduced back to thiol groups, thus thiol/disulfide homeostasis is preserved [10]. An automated analysis quantitatively measuring serum native and total thiol, and disulfides has been recently described as a method to determine dynamic thiol/ 
disulfide homeostasis [11]. It is easy to perform this new test in routine clinical laboratories, and it is a sensitive method to observe the oxidative stress status of the body.

Oxidative stress also affects the structure of the albumin, which is the most abundant protein in the plasma. The N-terminal region of albumin contains a binding location for transitional metal ions including cobalt and copper [12]. Ischemia and oxidative stress modify this terminal peptide region to an irreversible dysfunctional form known as ischemia-modified albumin (IMA). The level of IMA is associated with the degree of oxidative stress and also with the severity of the underlying disease [13, 14].

The objective of this study was to investigate serum IMA levels and dynamic thiol/disulfide homeostasis in PHN patients in order to determine whether oxidative stress, which plays an important role in the development of many diseases, is involved in the development of PHN, which occurs as a complication in $\mathrm{HZ}$.

\section{Materials and methods}

\section{Selection of participants}

A total of 29 patients admitted to a pain outpatient clinic and diagnosed with PHN between 2017 and 2018, and 30 age-matched control subjects at the same period of time were included in the study. Patients receiving any antiviral treatment in another hospital before the visit to our hospital, those receiving any anti-inflammatory analgesic drugs for pain control before the treatment and patients with irregular follow-up were excluded from the study. The control group consisted of healthy people without $\mathrm{HZ}$ who were not immunized for $\mathrm{HZ}$ within the last year and having no family or autoimmune disease history and who had similar age and gender distribution.

This study was approved by the local Ethics Committee of our hospital (ethics no: 2018/1500). Informed consent forms were received from all patients. Demographic data (age, gender), educational status and comorbidity status of the patients with PHN were questioned and recorded. Patients were also questioned about whether they were immunized for VZV after the diagnosis of $\mathrm{HZ}$ and how long after HZ they developed PHN. Pain intensity of the patients at admission was evaluated using the visual analogue scale (VAS). In addition, dermatomes with the pain localized were recorded. Blood samples were collected from the patients in order to evaluate disulfide/thiol homeostasis and IMA levels. Treatment plans of the patients were arranged by an algologist who was not included in the study. Medical and interventional treatment methods applied were recorded from the patient files.

\section{Plasma sampling, analytical procedure and laboratory methods}

Venous blood samples were collected through antecubital vein from the voluntary patient and control groups. Blood samples were centrifuged at $3500 \mathrm{rpm}$ for $10 \mathrm{~min}$ at $4{ }^{\circ} \mathrm{C}$ within $30 \mathrm{~min}$ after the sample collection from the participants. Serum obtained was kept frozen at $-80{ }^{\circ} \mathrm{C}$. Serum disulfide/thiol homeostasis measurements were made using the spectrophotometric method described by Erel and Neselioglu [11]. First, reducible disulfide bonds were reduced in order to form functional thiol groups. After reaction with 5,50-dithiobis-(2-nitrobenzoic acid) (DTNB), reducer sodium borohydride in the medium was depleted and removed using formaldehyde, and thus all thiol groups including reduced and native thiol groups were determined. Half of the difference between total thiol and native thiol was calculated as the disulfide level. After measuring native thiols $(\mathrm{SH})$ and total thiols $(\mathrm{SH}+\mathrm{SS})$ and the amount of disulfides (SS), disulfide/total thiol ratio (index 1), disulfide/native thiol ratio (index 2) and native thiol/total thiol ratio (index 3) were calculated.

The albumin cobalt binding test was used to measure serum IMA levels.

This test was carried out by addition of $50 \mathrm{~mL} 0.1 \%$ cobalt (II) chloride $\left(\mathrm{CoCl}_{2}, 6 \mathrm{H}_{2} \mathrm{O}\right)$ (Sigma-Aldrich Chemie $\mathrm{GmbH}$, Steinheim, Germany) to the patient serum. After centrifugation, serum samples were incubated for $10 \mathrm{~min}$ to allow binding of albumin to cobalt, and then $50 \mathrm{~mL}$ $1.5 \mathrm{mg} / \mathrm{mL}$ dithiothreitol (DDT) was added. After centrifugation and incubation for $2 \mathrm{~min}, 1.0 \mathrm{~mL} 0.9 \%$ sodium chloride solution was added to the milieu. Absorbance of the samples was read at $470 \mathrm{~nm}$ using a spectrophotometer, and the results were expressed in absorbance units (AU) [15]. Serum IMA/albumin ratio (IMAR) was also calculated.

\section{Statistical analysis}

Results of this study were analyzed using SPSS 19.0 software (IBM Corp., Armonk, NY, USA). Continuous values were expressed as mean \pm standard deviation (SD) and categorical values as number and percentage (n, \%). Normal distribution of the data was analyzed using the Kolmogorov-Smirnov test, histogram and \pm SD. Nonparametric data of the groups were compared using the 
Mann-Whitney U test and parametric data using the independent $\mathrm{T}$ test. Comparison of the categorical data was done using the chi-square test. Receiver operating characteristic (ROC) analyses were performed to test the ability of serum albumin, native thiol, total thiol, disulfide, index 1, index 2, index 3, IMA and IMAR to differentiate PHN patients from healthy controls. Optimal cut-off values were determined for each parameter, and sensitivity, specificity, positive predictive and negative predictive values were calculated. Linear regression analysis was used to determine independent predictors of thiol/disulfide parameters. Correlations between thiol-disulfide homeostasis parameters, albumin and IMA were evaluated using Spearman's correlation analysis. $\mathrm{p}<0.05$ values were considered statistically significant.

\section{Results}

\section{Demographic and clinical features of patients}

A total of 29 PHN patients and 30 control subjects were included in the study. The mean age was $56.89 \pm 15.19$ years in the PHN group (Group PHN) and $56.20 \pm 13.20$ years in the control group (Group C) $(\mathrm{p}=0.851)$. The female/ male ratio was 21/8 (72.4\%/27.6\%) in Group PHN and 21/9 $(70 \% / 30 \%)$ in Group C ( $\mathrm{p}=0.838)$. Of the PHN patients, 26 $(89.7 \%)$ were literate and three (10.3\%) were illiterate. Five (17.24\%) patients had accompanying malignancies. There were no other comorbidities in the PHN group except the aforementioned malignancies. While 25 patients in the control group were literate (83.3\%), five patients $(16.7 \%)$ were illiterate. There was no comorbidity in the control group. Considering the pain intensity on admission, the mean VAS score was $7.5 \pm 0.91$ (min-max: 6-10) in the PHN group. None of the patients were vaccinated for VZV. Time to PHN development following $\mathrm{HZ}$ was $3.6 \pm 1.03$ months (min-max: 3-6). Thoracal dermatoma was involved in $25(86.20 \%)$ patients. Interventional treatment modalities were performed in $13(44.82 \%)$ patients in addition to medical therapy.

\section{Laboratory outcomes of patients}

Serum IMA levels were $21 \pm 0.58 \mathrm{AU}$ and $0.75 \pm 0.09 \mathrm{AU}$ in the PHN and control groups, respectively, and the difference between the groups was statistically significant $(p<0.001)$. Serum total thiol concentrations were $421.62 \pm 90.28 \mu \mathrm{mol} / \mathrm{L}$ and $598.36 \pm 73.63 \mu \mathrm{mol} / \mathrm{L}$ in the PHN and control groups, respectively $(\mathrm{p}<0.001)$. Serum native thiol concentrations were $365.75 \pm 92.07 \mu \mathrm{mol} / \mathrm{L}$ and $531.90 \pm 72.9 \mu \mathrm{mol} / \mathrm{L}$ in the PHN and control groups, respectively $(\mathrm{p}<0.001)$. Serum disulfide concentrations were $33.23 \pm 5.33 \mu \mathrm{mol} / \mathrm{L}$ and $27.93 \pm 7.81 \mu \mathrm{mol} / \mathrm{L}$ in the PHN and control groups, respectively $(p=0.003)$. The native thiol/total thiol ratio was significantly lower, and the disulfide/total thiol and disulfide/native thiol ratios were significantly higher in the PHN group compared to the controls (Table 1, Figure 1).

\section{ROC analyses}

ROC analyses were performed to test the ability of dynamic thiol/disulfide parameters, IMA and IMAR to distinguish

Table 1: Comparison of total thiol-disulfide hemostasis parameters, albumin and IMA levels of the postherpetic neuralgia and control groups.

\begin{tabular}{|c|c|c|c|c|}
\hline & Group PHN $(n=29)$ & Group C $(n=30)$ & $95 \% \mathrm{Cl}$ lower/upper & p-Value \\
\hline Age, years & $56.89 \pm 15.19$ & $56.20 \pm 13.20$ & $-8.11 / 6.71$ & 0.851 \\
\hline Gender, F/M & $21 / 8(72.4 \% / 27.6 \%)$ & $21 / 9(70 \% / 30 \%)$ & & 0.838 \\
\hline Albumin, $\mathrm{mg} / \mathrm{dL}$ & $3.95 \pm 0.57$ & $5.33 \pm 0.49$ & $1.09 / 1.65$ & $<0.001$ \\
\hline IMA, AU & $1.21 \pm 0.58$ & $0.75 \pm 0.09$ & $-0.68 /-0.24$ & $<0.001$ \\
\hline IMAR (IMA/albumin), \% & $0.31 \pm 0.18$ & $0.14 \pm 0.02$ & $-0.240 /-0.106$ & $<0.001$ \\
\hline Native thiol, $\mu \mathrm{mol} / \mathrm{L}$ & $365.75 \pm 92.07$ & $531.90 \pm 72.9$ & $122.93 / 209.37$ & $<0.001$ \\
\hline Total thiol, $\mu \mathrm{mol} / \mathrm{L}$ & $421.62 \pm 90.28$ & $598.36 \pm 73.63$ & $133.86 / 219.62$ & $<0.001$ \\
\hline Disulfide, $\mu \mathrm{mol} / \mathrm{L}$ & $33.23 \pm 5.33$ & $27.93 \pm 7.81$ & $1.81 / 8.77$ & 0.003 \\
\hline Disulfide/total thiol, \% & $8.29 \pm 3.61$ & $6.38 \pm 1.52$ & $-3.34 /-0.47$ & 0.01 \\
\hline Disulfide/native thiol, \% & $6.95 \pm 2.58$ & $5.62 \pm 1.17$ & $-2.36 /-0.28$ & 0.013 \\
\hline Native thiol/total thiol, \% & $86.07 \pm 5.04$ & $88.74 \pm 2.34$ & $0.59 / 4.73$ & 0.013 \\
\hline
\end{tabular}

IMA, ischemia-modified albumin; AU, absorbance units; IMAR, ischemia-modified albumin/albumin ratio. 

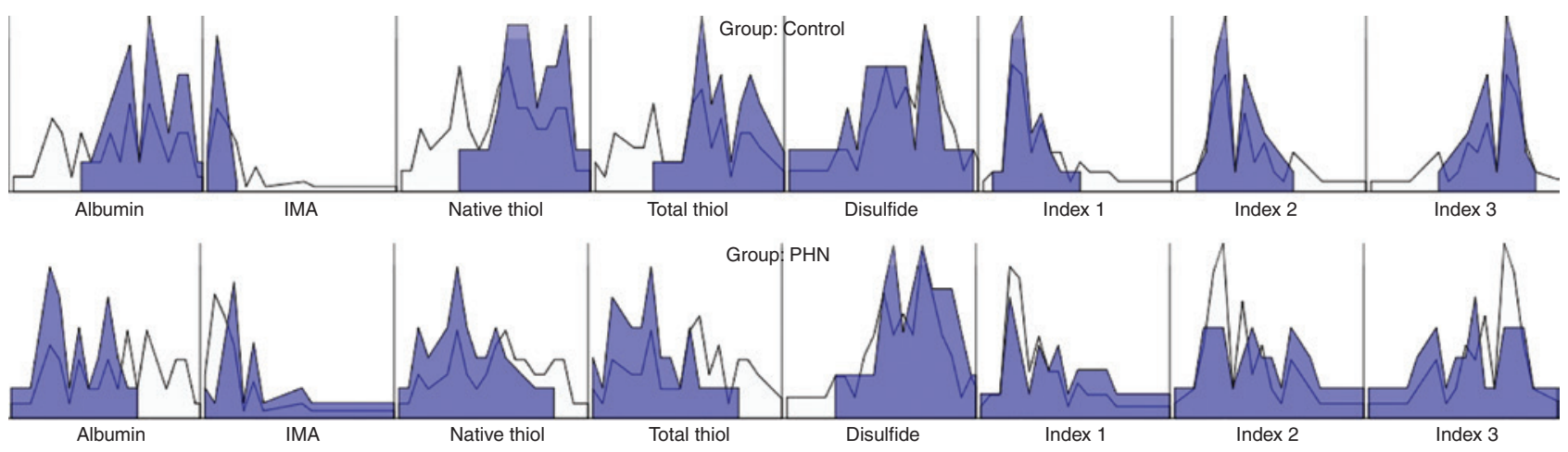

Figure 1: Serum thiol-disulfide homeostasis parameters, albumin and IMA levels of the groups.

IMA, ischemia-modified albumin; Index 1, disulfide/total thiol; Index 2, disulfide/native thiol; Index 3, native thiol/total thiol.

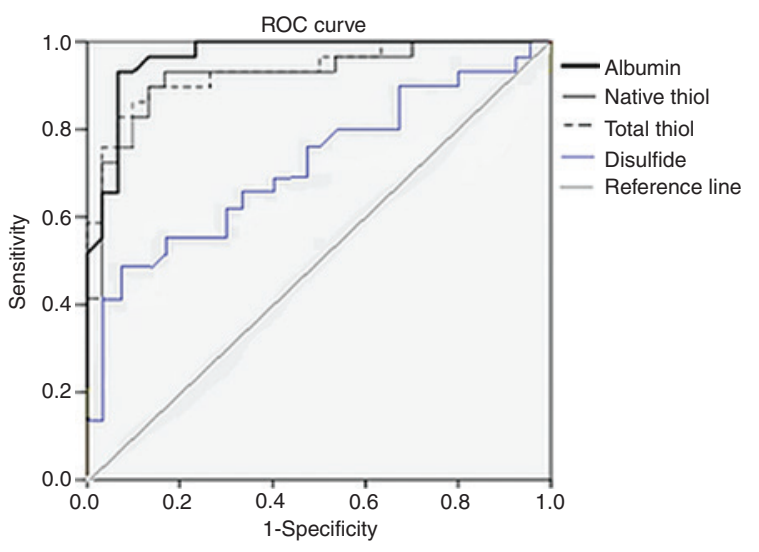

Figure 2: ROC curves for serum albumin, native thiol, total thiol and disulfide concentrations to differentiate postherpetic neuralgia patients from the healthy control group.

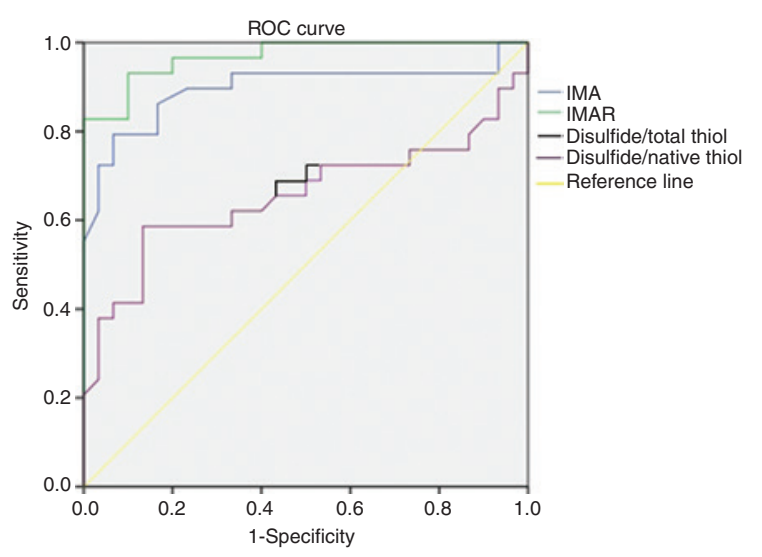

Figure 3: ROC curves for serum IMA, IMAR, disulfide/total thiol and disulfide/native thiol concentrations to differentiate postherpetic neuralgia patients from the healthy control group.

patients with PHN from healthy controls. ROC curves are given in Figures 2 and 3, and the results of the ROC analyses are summarized in Table 2.

\section{Regression/correlation analysis}

In the linear regression analysis, age was found to be an independent factor in the prediction of serum albumin (B: -0.022 ; $\beta$ : -0.582 ; 95\% confidence interval [CI]: $-0.044 /$ $-0.001 ; \mathrm{p}=0.044$ ), index 1 (B: 0.165; $\beta$ : 0.692; 95\% CI: 0.027/0.302; $p=0.022$ ), index 2 (B: 0.115; $\beta$ : 0.047; 95\% CI: $0.017 / 0.213 ; \mathrm{p}=0.024)$ and index $3(\mathrm{~B}:-0.228 ; \beta:-0.672$; 95\% CI: $-0.423 /-0.032 ; \mathrm{p}=0.025)$. On the other hand, the presence of malignancy was not an independent risk factor for elevated oxidative parameters.

There were significant correlations between thioldisulfide homeostasis parameters, IMA and serum albumin levels (Table 3).

\section{Discussion}

PHN is an important complication of $\mathrm{HZ}$ infection. Although there are several well-defined risk factors such as age, immunosuppression and cancer, the exact pathogenesis of $\mathrm{HZ}$ reactivation and PHN is still unknown. The results of our study show that serum total and native thiol concentrations were decreased and serum disulfide concentration was increased in PHN patients. Thiols have a negative standard reducing potential. Therefore, they function as rapid electron recipients. When an oxidant interacts with a thiol group, the thiol is oxidized to form a disulfide at the same time neutralizing the oxidant substance to relatively less toxic by-products. Plasma levels of total thiol, native thiol and disulfide are increasingly investigated in the clinical diagnosis and follow-up of numerous diseases and metabolic disorders [16, 17]. Our finding indicates the shifting of dynamic thiol/disulfide homeostasis toward the disulfide side which implies the presence of oxidative stress in PHN patients. 
Table 2: ROC analyses.

\begin{tabular}{|c|c|c|c|c|c|c|c|c|}
\hline & AUC & p-Value & $95 \% \mathrm{Cl}$ & Sensitivity & 1-specificity & +Predictive & -Predictive & Cut-off \\
\hline Albumin & 0.966 & $<0.001$ & $0.924-1000$ & 93.1 & 93.3 & 93.1 & 93.3 & 4.80 \\
\hline IMA & 0.897 & $<0.001$ & $0.804-0.989$ & 86.2 & 83.3 & 83.3 & 86.2 & 0.822 \\
\hline IMAR (IMA/albumin) & 0.969 & $<0.001$ & $0.932-1000$ & 93.1 & 90 & 90 & 93.1 & 0.17 \\
\hline Native thiol & 0.923 & $<0.001$ & $0.852-0.994$ & 89.7 & 86.7 & 86.7 & 89.6 & 462.5 \\
\hline Total thiol & 0.933 & $<0.001$ & $0.870-0.997$ & 86.2 & 90 & 89.2 & 87.1 & 518.25 \\
\hline Disulfide & 0.717 & 0.004 & $0.584-0.850$ & 55.2 & 83.3 & 76.2 & 65.8 & 28.02 \\
\hline Disulfide/total thiol & 0.659 & 0.036 & $0.510-0.809$ & 58.6 & 86.7 & 80.9 & 68.4 & 7.475 \\
\hline Disulfide/native thiol & 0.656 & 0.040 & $0.506-0.805$ & 58.6 & 86.7 & 80.9 & 68.4 & 6.505 \\
\hline Native thiol/total thiol & 0.657 & 0.038 & $0.508-0.807$ & 62.1 & 66.7 & 64.3 & 64.4 & 88.06 \\
\hline
\end{tabular}

IMA, ischemia-modified albumin; IMAR, ischemia-modified albumin/albumin ratio; AUC, area under curve; Cl, confidence interval.

Table 3: Correlations between thiol-disulfide homeostasis parameters, albumin and IMA.

\begin{tabular}{|c|c|c|c|c|c|c|c|c|}
\hline & IMA & IMAR & Native thiol & Total thiol & Disulfide & $\begin{array}{l}\text { Disulfide/ } \\
\text { total thiol }\end{array}$ & $\begin{array}{l}\text { Disulfide/ } \\
\text { native thiol }\end{array}$ & $\begin{array}{l}\text { Native thiol/ } \\
\text { total thiol }\end{array}$ \\
\hline \multirow[t]{2}{*}{ Albumin } & $\rho:-0.401^{\mathrm{b}}$ & $\rho:-0.607^{\mathrm{b}}$ & $\rho: 0.749^{b}$ & $\rho: 0.749^{\mathrm{b}}$ & $\rho: 0.200$ & $\rho:-0.450^{\mathrm{b}}$ & $\rho:-0.450^{b}$ & $\rho:-0.452^{\mathrm{b}}$ \\
\hline & $p=0.002$ & $\mathrm{p}<0.001$ & $\mathrm{p}<0.001$ & $\mathrm{p}<0.001$ & $p=0.129$ & $\mathrm{p}<0.001$ & $\mathrm{p}<0.001$ & $\mathrm{p}<0.001$ \\
\hline \multirow[t]{2}{*}{ IMA } & & $\rho: 0.933^{b}$ & $\rho:-0.210$ & $\rho:-0.248$ & $\rho:-0.365^{b}$ & $\rho: 0.019$ & $\rho:-0.044$ & $\rho: 0.045$ \\
\hline & & $\mathrm{p}<0.001$ & $p=0.110$ & $p=0.059$ & $p=0.004$ & $p=0.885$ & $p=0.736$ & $p=0.736$ \\
\hline \multirow[t]{2}{*}{ IMAR } & & & $\rho:-0.348^{b}$ & $\rho: 0.378^{b}$ & $\rho:-0.340^{b}$ & $\rho: 0.085$ & $\rho: 0.067$ & $\rho: 0.067$ \\
\hline & & & $p=0.007$ & $p=0.003$ & $p=0.008$ & $p=0.520$ & $p=0.615$ & $p=0.614$ \\
\hline \multirow[t]{2}{*}{ Native thiol } & & & & $\rho: 0.993^{b}$ & $\rho: 0.184$ & $\rho:-0.697^{b}$ & $\rho:-0.691^{b}$ & $\rho: 0.692^{b}$ \\
\hline & & & & $\mathrm{p}<0.001$ & $p=0.164$ & $\mathrm{p}<0.001$ & $\mathrm{p}<0.001$ & $\mathrm{p}<0.001$ \\
\hline \multirow[t]{2}{*}{ Total thiol } & & & & & $\rho: 0.297^{a}$ & $\rho:-0.617^{b}$ & $\rho:-0.607^{b}$ & $\rho: 0.608$ \\
\hline & & & & & $p=0.023$ & $\mathrm{p}<0.001$ & $\mathrm{p}<0.001$ & $\mathrm{p}<0.001$ \\
\hline \multirow[t]{2}{*}{ Disulfide } & & & & & & $\rho: 0.511^{b}$ & $\rho: 0.541^{b}$ & $\rho:-0.540^{\mathrm{b}}$ \\
\hline & & & & & & $\mathrm{p}<0.001$ & $\mathrm{p}<0.001$ & $\mathrm{p}<0.001$ \\
\hline \multirow[t]{2}{*}{ Disulfide/total thiol } & & & & & & & $\rho: 0.997^{b}$ & $\rho:-0.997^{b}$ \\
\hline & & & & & & & $\mathrm{p}<0.001$ & $p<0.001$ \\
\hline \multirow[t]{2}{*}{ Disulfide/native thiol } & & & & & & & & $\rho:-1.000$ \\
\hline & & & & & & & & $\mathrm{p}<0.001$ \\
\hline
\end{tabular}

IMA, ischemia-modified albumin; IMAR, ischemia-modified albumin/albumin ratio; $\rho$, Spearman's rho correlation coefficient. ${ }^{a} p<0.05$; ${ }^{\mathrm{b}} \mathrm{p}<0.001$.

Our results also show that serum IMA levels were increased in PHN patients. IMA is a marker of ischemia and also an indicator of oxidative stress. The metal-binding capacity of albumin $\mathrm{N}$-terminal decreases in acute ischemic conditions, and a variant protein known as IMA is formed [18]. Hypoxia/ischemia induces IMA by separation of the first two amino acids (Asp-Ala) of the N-terminal of the albumin which is a potent binding region for transitional metal ions $[19,20]$. IMA production is induced by direct stimulation of oxidative stress and serum IMA levels may immediately increase within an hour [20]. Serum IMA levels were shown to increase in several diseases associated with oxidative stress [21].

The results of the current study show that oxidative stress is present in PHN patients. Both the increase in serum IMA levels and the shift of dynamic thiol/ disulfide homeostasis toward the disulfide side are consistent with the presence of oxidative stress. Therefore, our results implicate that oxidative stress may contribute to the pathogenesis of PHN. There are only a few studies investigating the possible role of oxidative stress in $\mathrm{HZ}$ and PHN patients. Recently, Khazan et al. found that total antioxidant capacity and total polyphenol content levels were decreased and serum total oxidant status and oxidative stress index were increased in $\mathrm{HZ}$ patients [22]. In a meta-analysis conducted by Sebastiano et al., it was found that oxidative stress is increased across multiple tissues and species in vertebrates including mammals and humans. They also found that administration of antioxidants reduces virus yield, indicating that a condition of oxidative stress is favorable for the viral replication [23]. To the best of our knowledge, this is the first study 
in the literature to investigate dynamic thiol/disulfide homeostasis in PHN patients using the method of Erel and Neselioglu [11].

$\mathrm{HZ}$ occurs with the reactivation and replication of latent VZV in sensory ganglion obtained during primary infection [24]. It is characterized by a vesicular rash confined to a single dermatome. The pathogenesis underlying the reactivation of VZV is unclear. However, any factor affecting cell-mediated immunity may play a role in the reactivation of VZV. There is consensus on that T-cell immunity plays a key role in the control of the reactivation. The causes of $\mathrm{HZ}$ have been poorly defined [7, 9, 25]. Age, stress, immunodeficiency and immunosuppressive drugs are the known risk factors for virus reactivation [26]. Previous clinical and experimental studies have associated mental stress and related psychosocial factors with the risk for $\mathrm{HZ}$ as well as cell-mediated immunity [8, 27]. Exposing stress or corticostress during infection with VZV increases the risk of HZ development by suppressing CD8 + T cellular immune response [27-29]. HZ develops 3.6 times higher in persons with a lower VZV-specific cellmediated immunity (skin test with varicella antigen Biken $<5 \mathrm{~mm}$ ) than in individuals with a higher immunity (skin test with varicella antigen Biken $\geq 5 \mathrm{~mm}$ [30, 31].

Although $\mathrm{HZ}$ rash improves in a few weeks, $\mathrm{HZ}$ complications may be seen. PHN, which is defined as dermatomal pain persisting at least 3 months after the onset of $\mathrm{HZ}$ rash, is the most common complication [7]. The incidence of PHN is high following HZ. PHN1 has been reported in $19.5 \%$ of patients with $\mathrm{HZ}$ (pain persisting at least 1 month after rash onset), and PHN3 in 13.7\% of patients with $\mathrm{HZ}$ (pain persisting at least 3 months after rash onset) [32].

Age is the most prominent and widely accepted risk factor for PHN, but the role of sex is controversial. Understanding the role of age and gender in PHN is important, because these are primary vaccine-targeted (namely this can be defined before $\mathrm{HZ}$ episodes) patient characteristics. Some studies found no association with sex [9], while others have reported that women are more likely to develop PHN and a similar increase in possibility is seen by increasing age [33]. Independent of age, underlying diseases such as diabetes, congestive heart failure (CHF) or chronic obstructive pulmonary disease (COPD) and malignancy seem to increase the risk and severity of PHN [34-36]. In our study, the mean age of PHN patients was $56.89 \pm 15.19$ years (min-max: $25-88$ ), and the incidence of PHN was higher in female than in male patients. In the regression analysis, age was an independent risk factor in the prediction of the levels of albumin, indices 1, 2 and 3, while malignancy was not evaluated as an independent risk factor for the elevation of oxidative parameters.
In this study, sensitivity and specificity values calculated for IMA, IMAR, native thiol and total thiol in order to distinguish PHN patients from the healthy controls were high.

Our results show that changes in serum native thiol/ total thiol ratio, disulfide/total thiol ratio and disulfide/ native thiol ratio were significant. In addition to individual measurements of serum native thiol, total thiol or disulfide concentration, determination of all parameters of dynamic thiol/disulfide homeostasis using Erel and Neselioglu's method may be appropriate in PHN patients.

One of the limitations of the current study was the fact that healthy controls were selected on the basis of medical history and detailed physical examination. Detailed laboratory tests were not performed in the control group.

In conclusion, disulfide/thiol homeostasis of PHN patients is disrupted, and shifts toward the disulfide side, which supports oxidative stress in the pathogenesis of the disease. Further studies are needed in order to clarify pathophysiological mechanisms underlying this disease. A better understanding of these mechanisms will facilitate development of new strategies in the prevention of PHN.

Author contributions: All the authors have accepted responsibility for the entire content of this submitted manuscript and approved submission.

Research funding: None declared.

Employment or leadership: None declared.

Honorarium: None declared.

Competing interests: The funding organization(s) played no role in the study design; in the collection, analysis, and interpretation of data; in the writing of the report; or in the decision to submit the report for publication.

\section{References}

1. Arvin AM. Varicella-zoster virus. Clin Microbiol Rev 1996;9: 361-81.

2. Weitzman D, Shavit O, Stein M, Cohen R, Chodick G, Shalev V. A population based study of the epidemiology of herpes zoster and its complications. J Infect 2013;67:463-9.

3. Esteban-Vasallo MD, Domínguez-Berjón MF, Gil-Prieto R, AstrayMochales J, Gil de Miguel A. Sociodemographic characteristics and chronic medical conditions as risk factors for herpes zoster: a population-based study from primary care in Madrid (Spain). Hum Vaccin Immunother 2014;10:1650-60.

4. Chen SY, Suaya JA, Li Q, Galindo CM, Misurski D, Burstin S, et al. Incidence of herpes zoster in patients with altered immune function. Infection 2014;42:325-34.

5. Harpaz R, Leung JW, Brown CJ, Zhou FJ. Psychological stress as a trigger for herpes zoster: might the conventional wisdom be wrong? Clin Infect Dis 2015;60:781-5. 
6. Schmader K, Studenski S, MacMillan J, Grufferman S, Cohen HJ. Are stressful life events risk factors for herpes zoster? J Am Geriatr Soc 1990;38:1188-94.

7. Johnson RW, Rice AS. Clinical practice Postherpetic Neuralgia. N Engl J Med 2014;371:1526-33.

8. Truckenmiller ME, Bonneau RH, Norbury CC. Stress presents a problem for dendritic cells: corticosterone and the fate of MHC class I antigen processing and presentation. Brain Behav Immun 2006;20:210-8.

9. Forbes HJ, Thomas SL, Smeeth L, Clayton T, Farmer R, Bhaskaran $\mathrm{K}$, et al. A systematic review and meta-analysis of risk factors for postherpetic neuralgia. Pain 2016;157:30-54.

10. Banne AF, Amiri A, Pero RW. Reduced level of serum thiols in patients with a diagnosis of active disease. J Anti Aging Med 2003;6:327-34.

11. Erel O, Neselioglu S. A novel and automated assay for thiol/ disulphide homeostasis. Clin Biochem 2014;47:326-32.

12. Sokolowska M, Krezel A, Dyba M, Szewczuk Z, Bal W. Short peptides are not reliable models of thermodynamic and kinetic properties of the $\mathrm{N}$-terminal metal binding site in serum albumin. Eur J Biochem 2002;4:1323-31.

13. Roy D, Quiles J, Gaze DC, Collinson P, Kaski JC, Baxter GF. Role of reactive oxygen species on the formation of the novel diagnostic marker ischaemia modified albumin. Heart 2006;92:113-4.

14. Sitar ME, Aydin S, Akatay UC. Human serum albumin and its relation with oxidative stress. Clin Lab 2013;59:945-52.

15. Bar-Or D, Lau E, Winkler JV. A novel assay for cobalt albumin binding and its potential as a marker for myocardial ischemia a preliminary report. J Emerg Med 2000;19:311-5.

16. Guney T, Kanat IF, Alkan A, Alisik M, Akinci S, Silay K, et al. Assessment of serum thiol/disulfide homeostasis in multiple myeloma patients by a new method. Redox Rep 2016;19:1-6.

17. Asil M, Dertli R, Biyik M, Yolacan R, Erel O, Neselioglu S, et al. Dynamic thiol-disulfide homeostasis is disturbed in patients with non-alcoholic fatty liver disease. J Lab Med 2018;42:31-8.

18. Lippi G, Montagnana M, Guidi GC. Albumin cobalt binding and ischemia modified albumin generation: an endogenous response to ischemia? Int J Cardiol 2006;14:410-1.

19. Gaze DC. Ischemia modified albumin: a novel biomarker for the detection of cardiac ischemia. Drug Metab Pharmacokinet 2009;24:333-41.

20. Morrow DA, De Lemos JA, Sabatine MS, Antman EM. The search for a biomarker of cardiac ischemia. Clin Chem 2003;49:537-9.

21. Yavuz F, Biyik M, Asil M, Dertli R, Demir A, Polat H, et al. Serum ischemic modified albumin (IMA) concentration and IMA/ albumin ratio in patients with hepatitis B-related chronic liver diseases. Turk J Med Sci 2017;47:947-53.

22. Khazan M, Hedayati M, Robati RM, Riahi SM, Nasiri S. Impaired oxidative status as a potential predictor in clinical manifestations of herpes zoster. J Med Virol 2018;90:1604-10.
23. Sebastiano M, Chastel O, de Thoisy B, Eens M, Costantini D. Oxidative stress favours herpes virus infection in vertebrates: $a$ meta-analysis. Curr Zool 2016;62:325-32.

24. Arvin AM. Humoral and cellular immunity to varicella-zoster virus: an overview. J Infect Dis 2008;197:58-60.

25. Johnson RW, Alvarez-Pasquin MJ, Bijl M, Franco E, Takao Y, Okuno Y, et al. Associations of perceived mental stress, sense of purpose in life, and negative life events with the risk of incident herpes zoster and postherpetic neuralgia: the SHEZ study. Am J Epidemiol 2018;187:251-9.

26. Johnson RW, Alvarez-Pasquin MJ, Bijl M, Franco E, Gaillat J, Clara JG, et al. Herpes zoster epidemiology, management, and disease and economic burden in Europe: a multidisciplinary perspective. Ther Adv Vaccines 2015;3:109-20.

27. Elftman MD, Hunzeker JT, Mellinger JC, Bonneau RH, Norbury CC, Truckenmiller ME. Stress-induced glucocorticoids at the earliest stages of herpes simplex virus-1 infection suppress subsequent antiviral immunity, implicating impaired dendritic cell function. J Immunol 2010;184:1867-75.

28. Oxman MN. Zoster vaccine: current status and future prospects. Clin Infect Dis 2010;51:197-213.

29. Levin MJ, Smith JG, Kaufhold RM, Barber D, Hayward AR, Chan $\mathrm{CY}$, et al. Decline in varicellazoster virus (VZV)-specific cellmediated immunity with increasing age and boosting with a high-dose VZV vaccine. J Infect Dis 2003;188:1336-44.

30. The Shozu Herpes Zoster (SHEZ) Study: assessment of skin test with varicella skin test antigen "BIKEN" for predicting the risk of herpes zoster and post-herpetic neuralgia. Community based prospective cohort study [in Japanese]. Rinshoiyaku 2014;30:905-15.

31. Asada H, Nagayama K, Okazaki A, Mori Y, Okuno Y, Takao Y, et al. An inverse correlation of VZV skin-test reaction, but not antibody, with severity of herpes zoster skin symptoms and zoster-associated pain. J Dermatol Sci 2013;69:243-9.

32. Gauthier A, Breuer J, Carrington D, Martin M, Rémy V. Epidemiology and cost of herpes zoster and post-herpetic neuralgia in the united kingdom. Epidemiol Infect 2009;137:38-47.

33. Muñoz-Quiles C, López-Lacort M, Orrico-Sánchez A, DíezDomingo J. Letter to the editor regarding "The role of age-sex interaction in the development of post-herpetic neuralgia". Hum Vaccin Immunother 2018;14:906-8.

34. Muñoz-Quiles C, López-Lacort M, Ampudia-Blasco FJ, DíezDomingo J. Risk and impact of herpes zoster on patients with diabetes: a population-based study, 2009-2014. Hum Vaccin Immunother 2017;13:2606-11.

35. Forbes HJ, Bhaskaran K, Thomas SL, Smeeth L, Clayton T, Langan SM. Quantification of risk factors for herpes zoster: population based case-control study. BMJ (Clin Res Ed) 2014;348:2911.

36. Forbes HJ, Bhaskaran K, Thomas SL, Smeeth L, Clayton T, Mansfield K, et al. Quantification of risk factors for postherpetic neuralgia in herpes zoster patients: a cohort study. Neurology 2016;87:94-102. 